
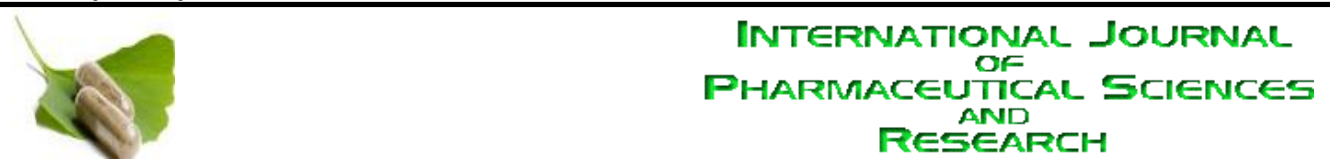

Received on 07 June, 2011; received in revised form 23 July, 2011; accepted 28 September, 2011

\title{
PREPARATION AND CHARACTERIZATION OF MESALAMINE SOLID DISPERSIONS BY KNEADING METHOD
}

\author{
Lalit Jejurkar* and K. K. Tapar
}

Vidyabharti College of Pharmacy, Department of Pharmaceutics (PG \& Research), Amravati, Maharashtra, India

\begin{abstract}
Keywords:

Kneading Method,

Sodium lauryl sulphate, Urea,

Solid Dispersion

Correspondence to Author:

Lalit Jejurkar

Vidyabharti College of Pharmacy, Department of Pharmaceutics (PG \& Research), CK Naidu Road, Amravati, Maharashtra, India

The purpose of the study was to improve the physicochemical properties of Mesalamine like solubility and dissolution rate by forming solid dispersions with sodium lauryl sulphate (SLS) and Urea (UR) as water-soluble carriers. The solid dispersion of Mesalamine by kneading method were prepared using 1:1, $1: 2$ and 1:3 ratios of drug to polymer using methanol as solvent. Characterization of Mesalamine solid dispersion was performed by Fourier Transform Infrared (FTIR) spectroscopy and X-ray powder diffractometry study. FTIR spectra reveal that there was no drug - carrier interaction and absence of Mesalamine peaks in XRD profile suggests the transformation of crystalline Mesalamine to amorphous form. The saturation Solubility study was carried out by using flask shaker method at room temperature. Dissolution study was conducted in $0.1 \mathrm{~N} \mathrm{HCl}$ at $37^{\circ} \mathrm{C} \pm 0.5^{\circ} \mathrm{C}$ using USP type II (paddle) type dissolution apparatus. The prepared dispersion showed marked increase the saturation solubility and dissolution rate of Mesalamine than that of drug alone. Therefore the dissolution rate of poorly water soluble drug Mesalamine can be significantly enhanced by the preparation of solid dispersion using SLS and UR by kneading technique.
\end{abstract}

INTRODUCTION: Mesalamine is 5-amino salicylic acid, active moiety of sulphasalazine. Its major indications are to treat mild to moderate acute exacerbations of ulcerative colitis's in remission, particularly in patients intolerant of sulphasalazine. It is white to pinkish crystals slightly soluble in water, 20 to $30 \%$ absorbed following oral administrations.

Together with the permeability, the solubility behavior of a drug is a key determinant of its oral bioavailability. There have always been certain drugs for which solubility has presented a challenge to the development of a suitable formulation for oral administration. Examples such as griseofulvin, digoxin, phenytoin, sulphathiazole and chloramphenicol come immediately to mind. With the recent advent of high throughput screening of potential therapeutic agents, the number of poorly soluble drug candidates has risen sharply and the formulation of poorly soluble compounds for oral delivery now presents one of the most frequent and greatest challenges to formulation scientists in the pharmaceutical industry ${ }^{1,2}$.

Urea is the end product of human protein metabolism, has a light diuretic effect and is regarded as non-toxic. Its solubility in water is greater than 1 in 1 and it also exhibits good solubility in many common organic solvents. In one of the first bioavailability studies of solid dispersions, it was shown that sulphathiazole was better absorbed in rabbits when given as a eutectic with urea ${ }^{2}$. Similarly, Goldberg et al., ${ }^{3}$ reported faster dissolution rates of chloramphenicol when prepared 
with urea as the carrier. The release of naproxen from solid dispersions in PEG 4000, 6000 and 20000 could be further enhanced when either sodium lauryl sulphate (SLS) or Tween 80 (a polyethylene sorbitan fatty acid ester) was added to the system ${ }^{4}$. Punitha $S$ et al., studied the use of Urea as a carrier for solid dispersion of Celecoxib ${ }^{5}$.

The purpose of this study was to prepare solid dispersion by Kneading method, to improve the dissolution rate of Mesalamine. It was postulated that, if the drug is only slightly soluble in water, the dissolution process could be the rate-limiting step in the absorption of drug thus resulting in poor bioavailability.

In the present study, two different compounds were chosen as carriers to prepare solid dispersion systems with the Mesalamine like SLS and Urea. All solid dispersion systems were prepared in 1:1, 1:2 and 1: 3 drug to polymer ratio. Studies were initiated to evaluate the saturation solubility, in-vitro dissolution Kinetics, FTIR and X-ray powder diffraction.

MATERIALS AND METHODS: Mesalamine was obtained as gift sample from Sun Pharmaceutical Ltd, Gujarat. All the other chemicals and solvents of laboratory grade were purchased from Loba chemicals, Mumbai, and were used as it is.

Methods for Preparation of Solid Dispersion of Mesalamine (Kneading Method): Mesalamine and the various water soluble carriers (SLS and Urea) were weighed in different ratio 1:1, 1:2, and $1: 3$ and transferred to mortar for kneading using hot water up to 45 minutes. Sufficient methanol was being added to maintain paste like consistency. The resulting paste was then dried in hot air oven at $45 \circ \mathrm{C}$ for 24 hours. The dried dispersions were milled and passed through sieve No. 18. The prepared dispersions were stored in glass vials and used for further studies.

\section{Detection of Drug Content in prepared Dispersions ${ }^{\mathbf{9}}$ :}

Three samples each of prepared Mesalamine dispersions equivalent to $100 \mathrm{mg}$ of Mesalamine were accurately weighed, crushed and transferred to $100 \mathrm{ml}$ standard conical flask and the volume was made up to $100 \mathrm{ml}$ with Phosphate buffer $\mathrm{pH}$ 6.8, filtered through Whatmann filter paper and absorbance was taken at $331.0 \mathrm{~nm}$.
Physicochemical characterization of prepared Solid Dispersions:

Solubility Determination: Solubility study was carried out by using flask shaker method. Excess Mesalamine and its different dispersions were introduced separately into the amber colored vials with $25 \mathrm{ml}$ capacity, each containing $25 \mathrm{ml}$ of distilled water and shaked for 24 hours at room temperature. The content of each bottle was then filtered through Whatmann filter paper. The filtrate was then diluted with distilled water and assayed spectrophotometrically at $230 \mathrm{~nm}$ (UV-visible Spectrophotometer-Shimadzu 1601). Solubility of each sample was determined in triplicate. Results are shown in table 1 and 2. Fig. 1 shows a comparative phase solubility study.

\section{TABLE 1: CODES FOR SOLID DISPERSION}

\begin{tabular}{cc}
\hline Solid Dispersion Systems & Codes For Dispersion \\
\hline Mesalamine & $\mathrm{PD}$ \\
Mesalamine: SLS (1:1) & $\mathrm{S}_{1}$ \\
Mesalamine: SLS (1:2) & $\mathrm{S}_{2}$ \\
Mesalamine: SLS (1:3) & $\mathrm{S}_{3}$ \\
Mesalamine: Urea (1:1) & $\mathrm{U}_{1}$ \\
Mesalamine: Urea (1:2) & $\mathrm{U}_{2}$ \\
Mesalamine: Urea (1:3) & $\mathrm{U}_{3}$ \\
\hline
\end{tabular}

TABLE 2: SOLUBILITY ANALYSIS OF MESALAMINE AND ITS SOLID DISPERSION IN DISTILLED WATER

\begin{tabular}{cc}
\hline Code For Dispersion & Solubility (in $\mathrm{mg} / \mathrm{ml}$ ) Mean \pm S.D \\
\hline $\mathrm{PD}$ & $1.09 \pm 0.026 \mathrm{mg} / \mathrm{ml}$ \\
$\mathrm{U}_{1}$ & $1.1 \pm 0.016 \mathrm{mg} / \mathrm{ml}$ \\
$\mathrm{U}_{2}$ & $1.236 \pm 0.037 \mathrm{mg} / \mathrm{ml}$ \\
$\mathrm{U}_{3}$ & $1.863 \pm 0.054 \mathrm{mg} / \mathrm{ml}$ \\
$\mathrm{S}_{1}$ & $1.681 \pm 0.033 \mathrm{mg} / \mathrm{ml}$ \\
$\mathrm{S}_{2}$ & $1.698 \pm 0.014 \mathrm{mg} / \mathrm{ml}$ \\
$\mathrm{S}_{3}$ & $1.991 \pm 0.025 \mathrm{mg} / \mathrm{ml}$ \\
\hline
\end{tabular}

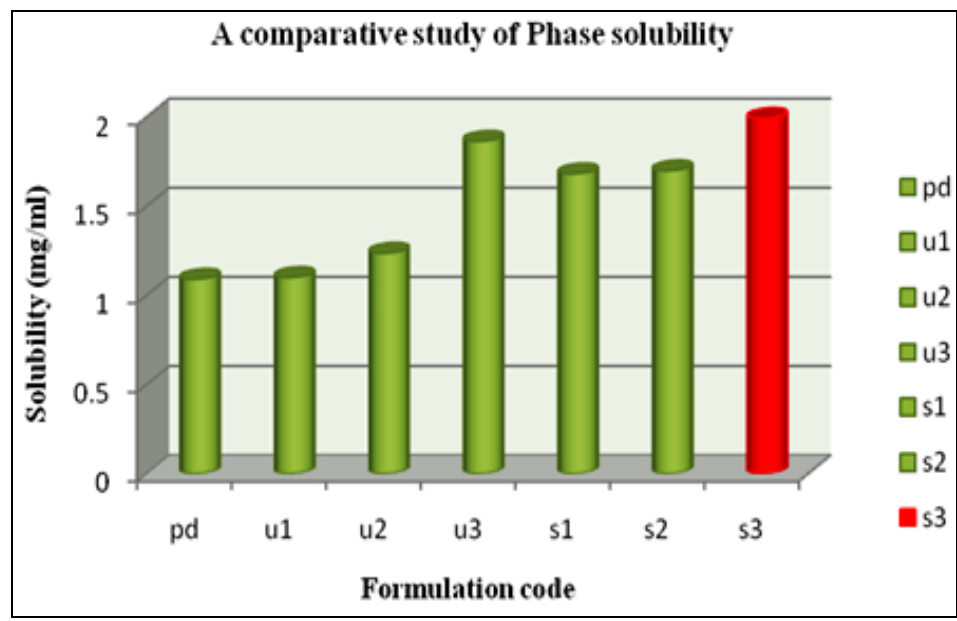

FIG. 1: A COMPARATIVE STUDY OF PHASE SOLUBILITY 
Fourier Transforms Infrared Spectroscopy (FT-IR): FTIR by Toshwin Analytical Pvt. Ltd. Mumbai using was recorded using FTIR was recorded using potassium bromide discs. Fig. 2-6 shows the FTIR SHIMADZU Fourier Transform Infrared Spectroscopy spectra's of PD, Urea, U3, SLS pure, and S3 Model FTIR 8400S, Sr. No-210141005.38 LP, supplied respectively.

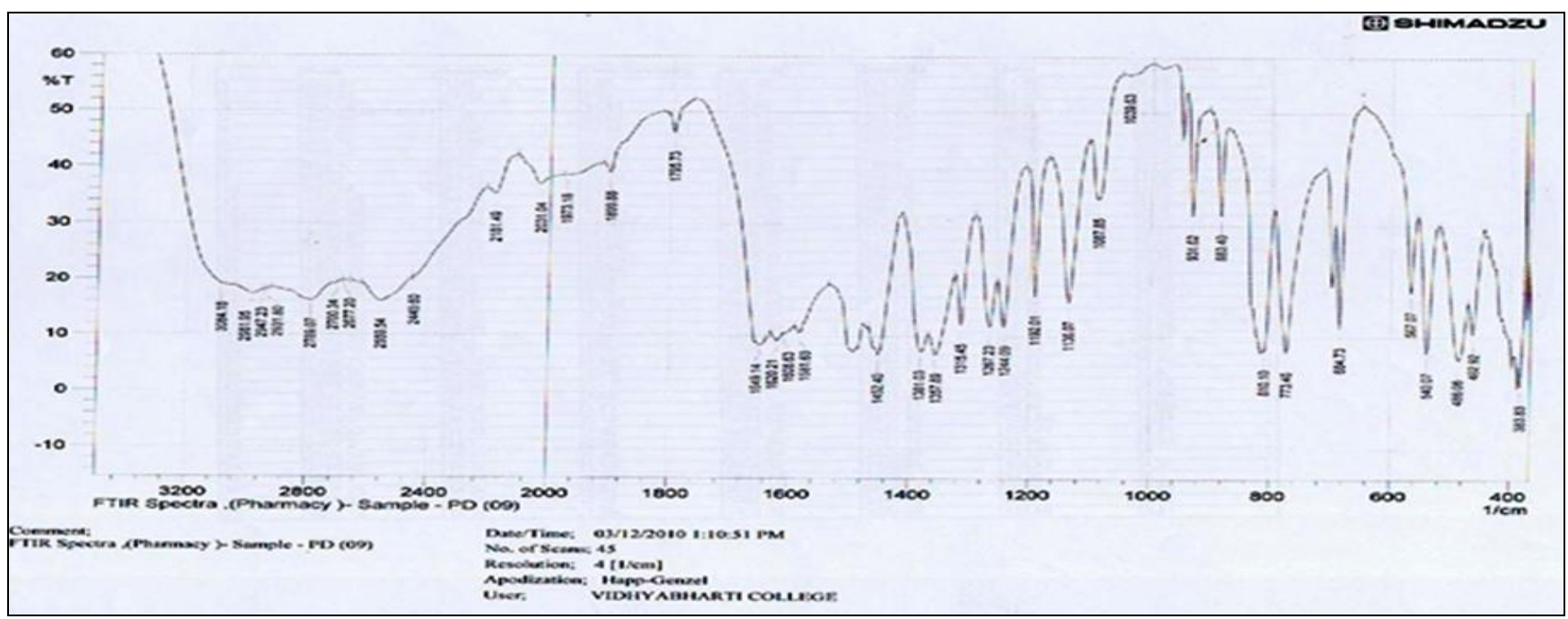

FIG. 2: FTIR SPECTRA OF PD

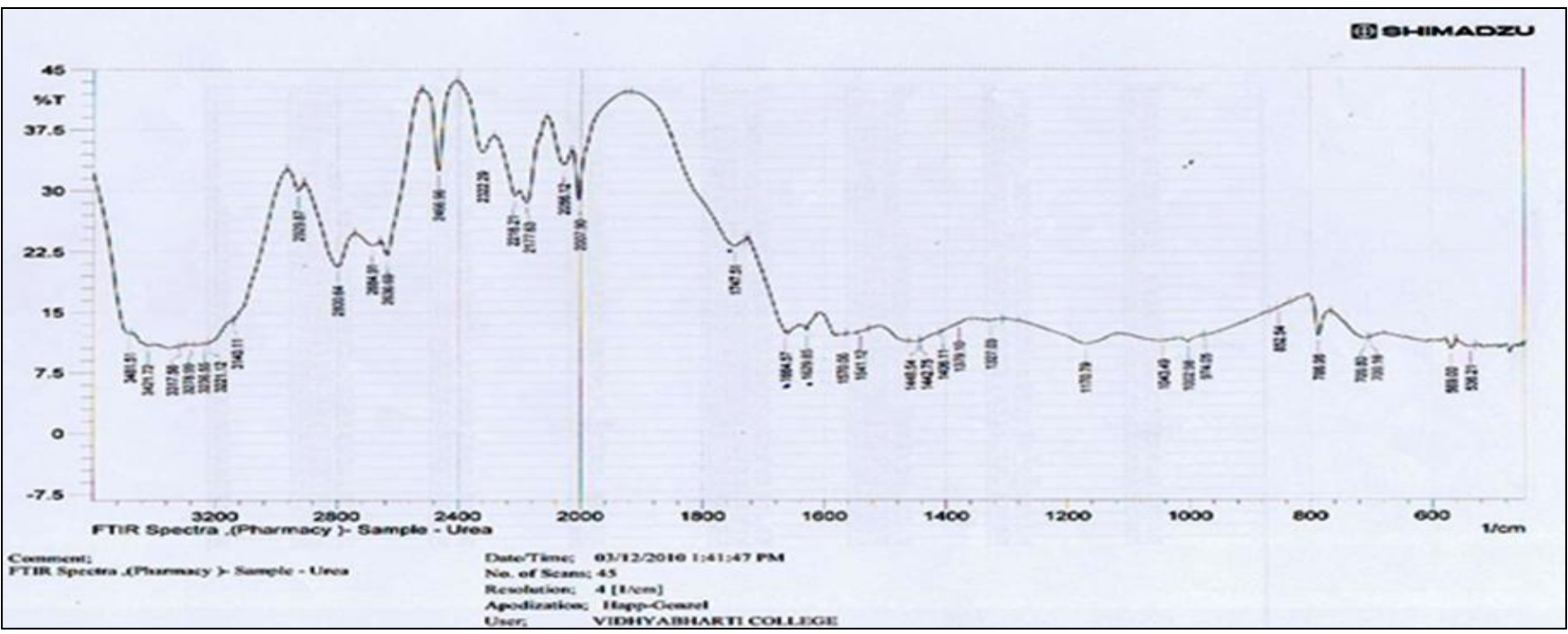

FIG. 3: FTIR SPECTRA OF UREA

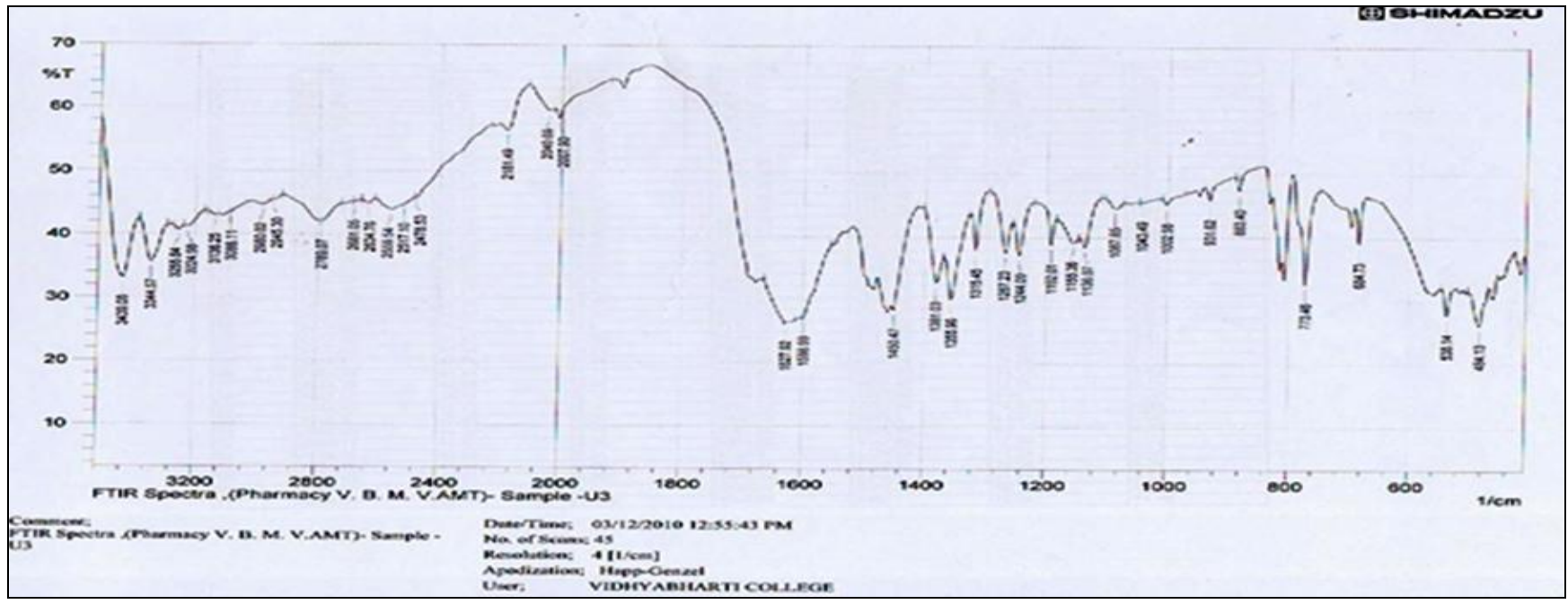

FIG. 4: FTIR SPECTRA of U3 


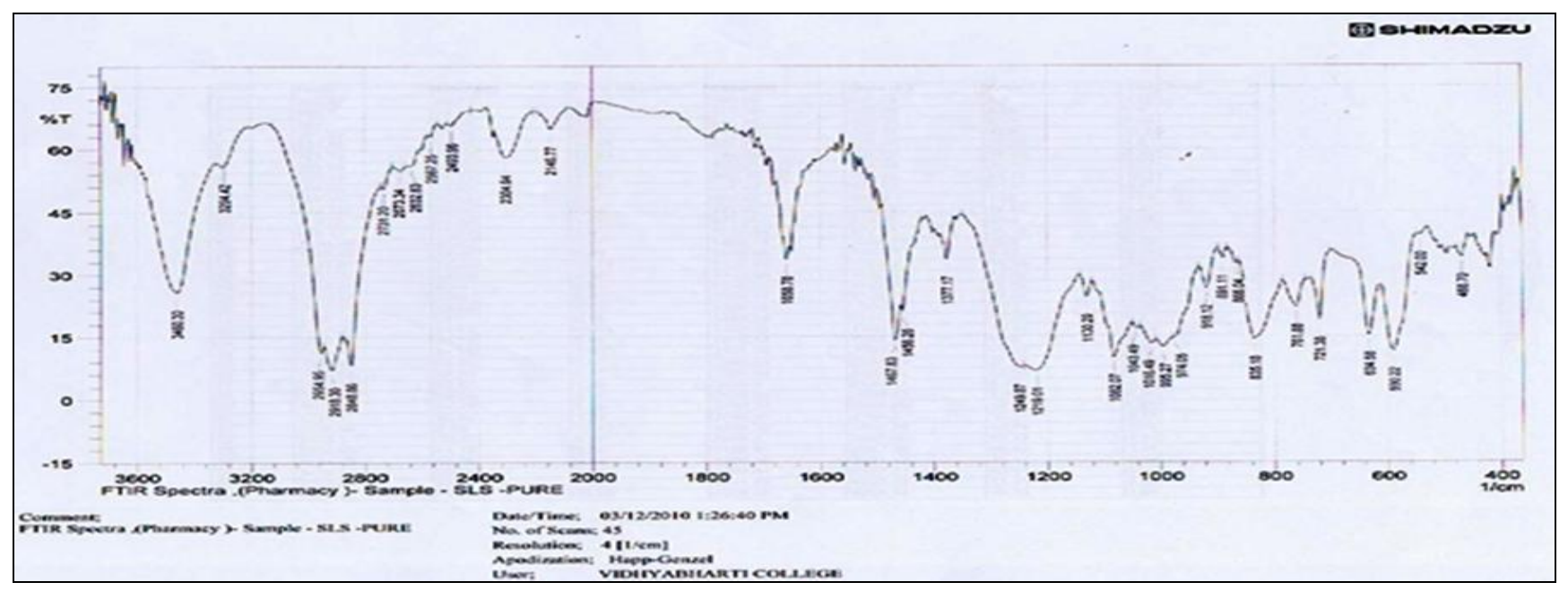

FIG. 5: FTIR SPECTRA OF SLS PURE

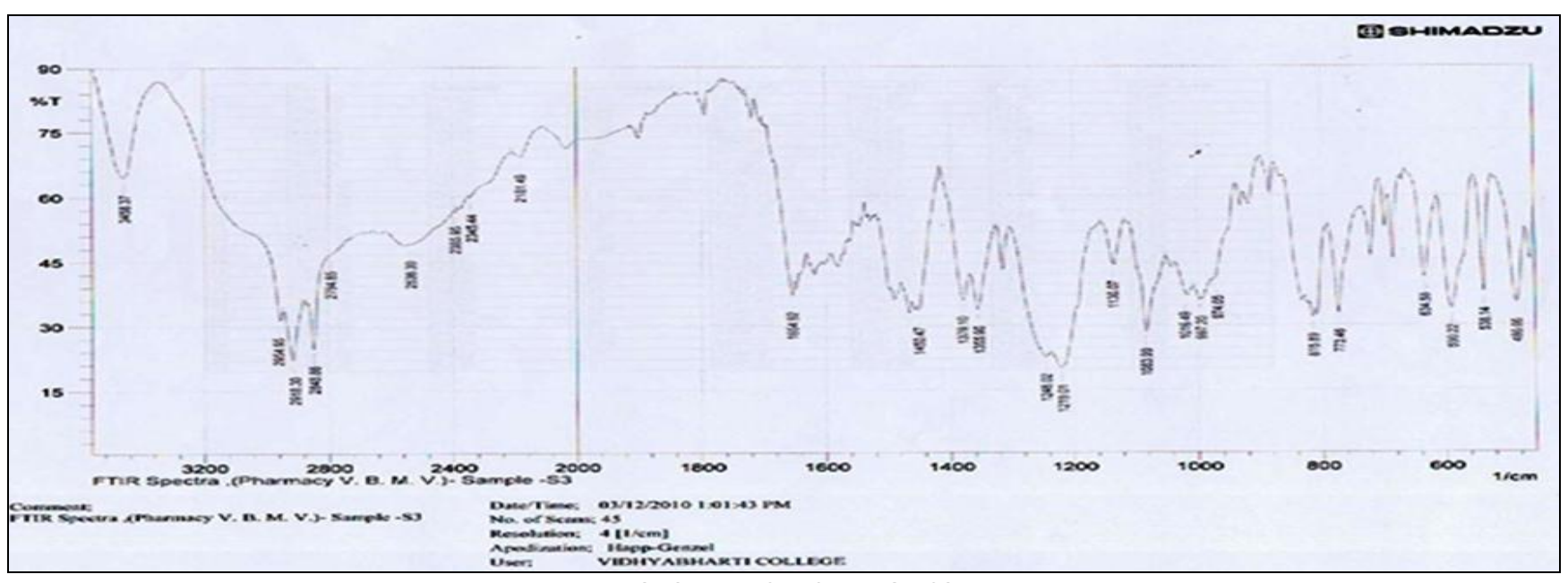

FIG. 6: FTIR SPECTRA OF S3

Powder X-ray diffraction: The cavity of the metal sample holder of $\mathrm{x}$-ray diffractometer was filled with the ground sample powder and then smoothened with a spatula. X-ray diffractograms of Mesalamine and its dispersion samples were obtained using a Philips Analytical X Part PRD / SRS Division, N.B.B.S. and L.U.P, from Nagpur. A scanning rate of $0.042 \theta$ s-1 over the range of $10-6002 \theta$ by using $\mathrm{CuK} \propto$ as tube anode having wavelength $1.5418 \mathrm{~A} 0$ was used to record each spectrum. Fig.7, 8, 9 shows XRD spectras of PD, U3 and S3 respectively.

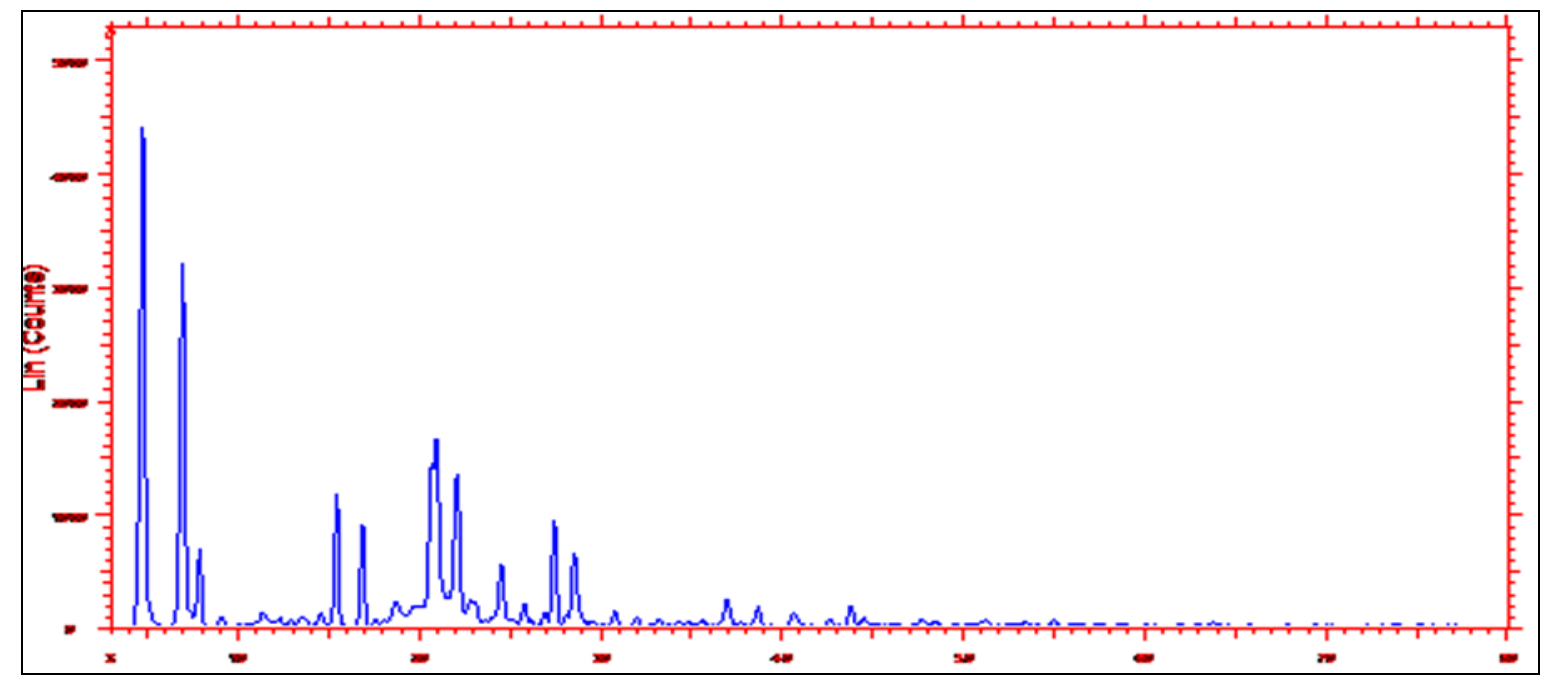

FIG. 3: XRD SPECTRA OF PURE DRUG (PD) 


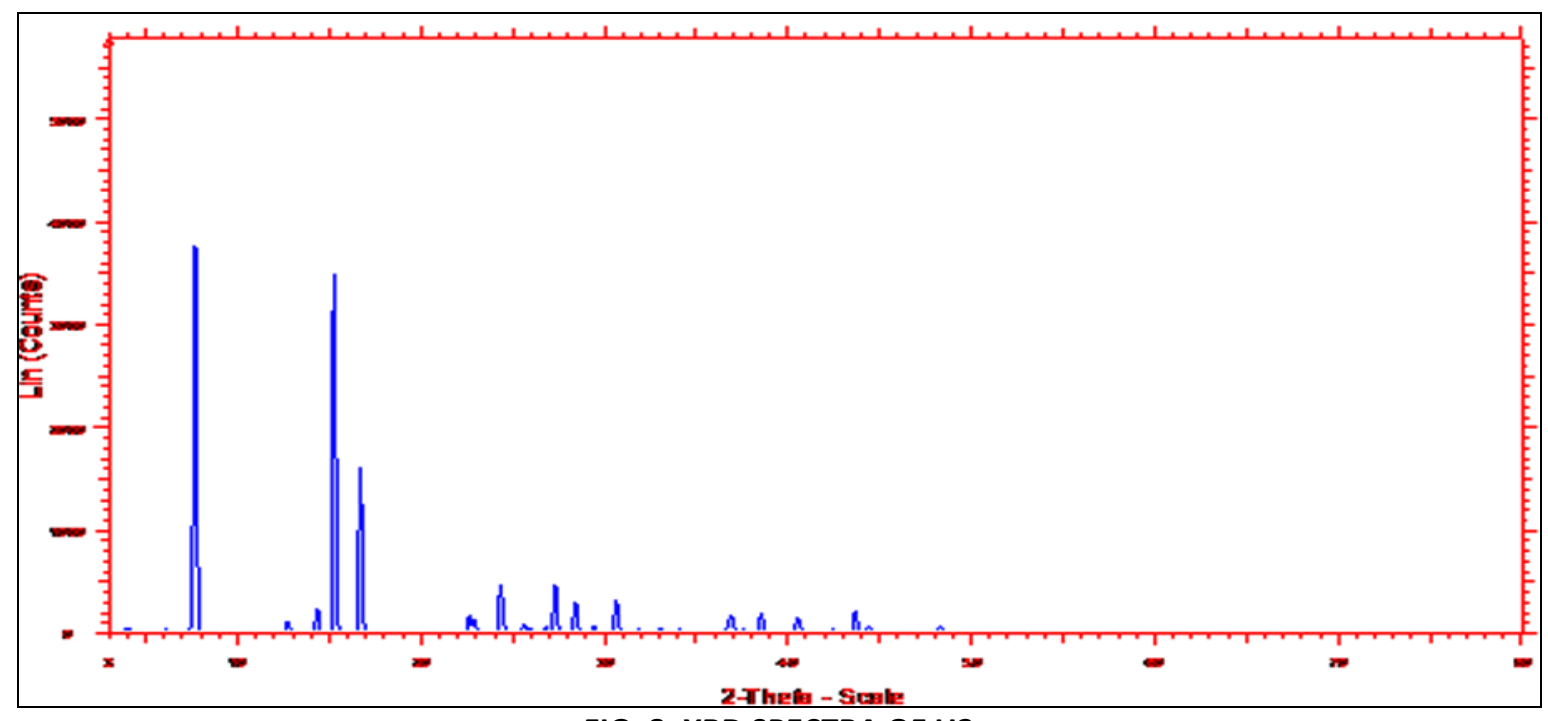

FIG. 8: XRD SPECTRA OF U3

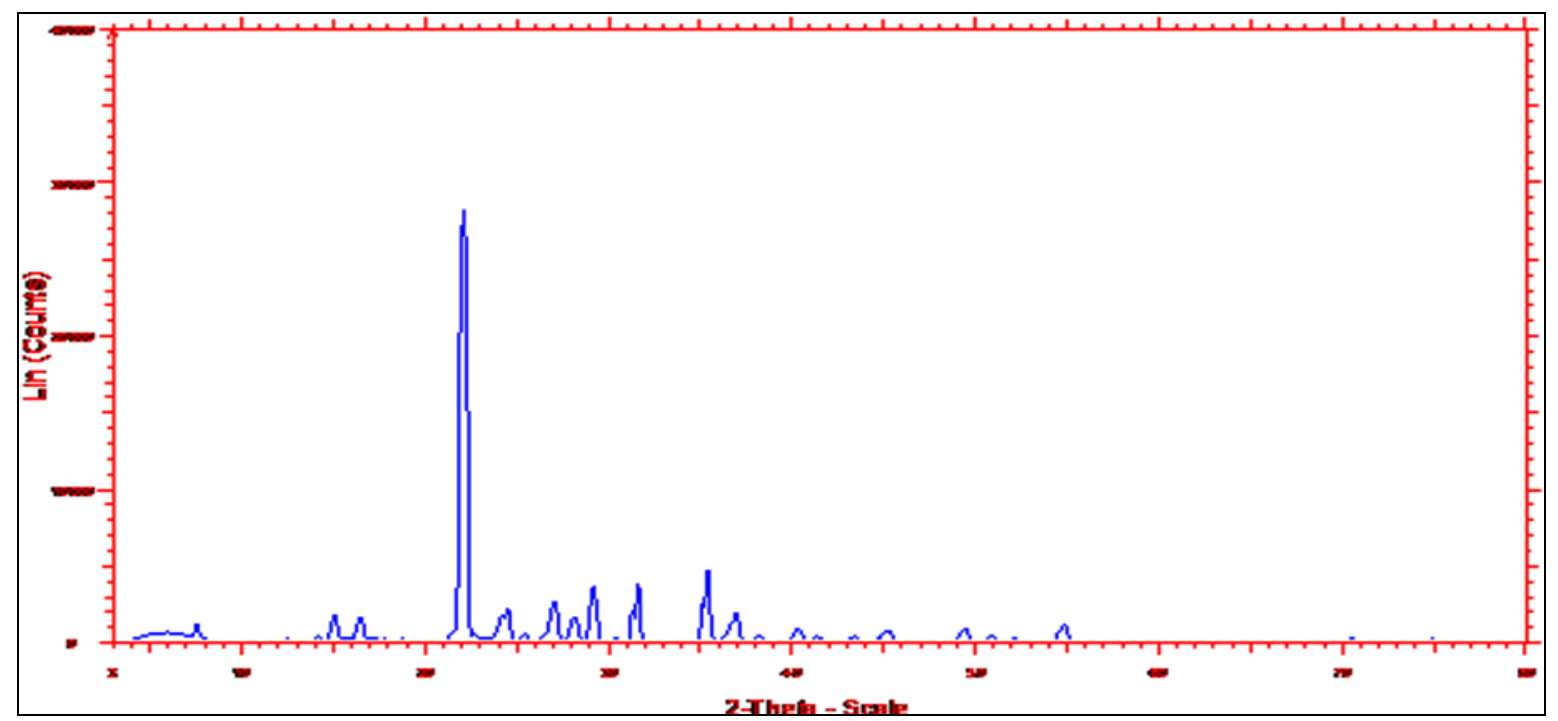

FIG. 9: XRD SPECTRA OF S3

Dissolution Studies: The dissolution test was carried out by using USP-II (rotating paddle). The dissolution conditions includes, Dissolution medium (Phosphate buffer $\mathrm{pH}$ 6.8), Temperature $\left(37^{\circ} \mathrm{C} \pm 0.5^{\circ} \mathrm{C}\right)$, Speed of Rotation (50 rpm), Volume of Medium (900 ml.). Mesalamine containing prepared solid dispersions equivalent to $50 \mathrm{mg}$ were placed in the basket of dissolution medium and the apparatus was run. The 10 $\mathrm{ml}$ aliquot was withdrawn at interval of every $5 \mathrm{~min}$. up to $30 \mathrm{~min}$. After withdrawing each sample same amount of drug free dissolution medium was replaced so as to maintain sink condition. The samples were filtered through Whatmann filter paper and absorbance was recorded at $331.0 \mathrm{~nm}$. The data obtained is shown in figure 10.

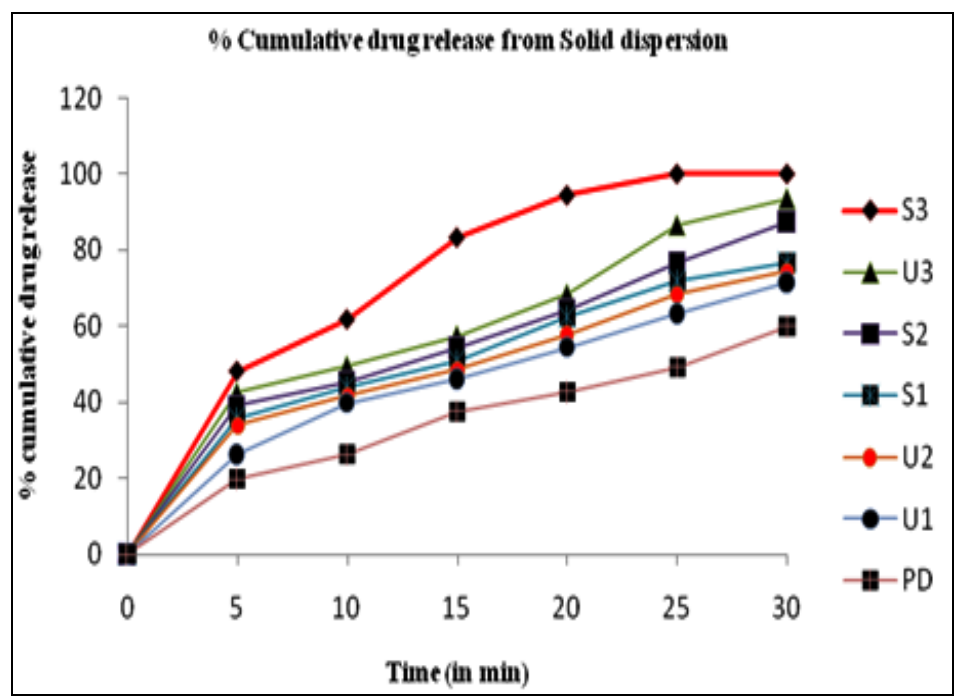

FIG. 4: IN VITRO RELEASE STUDY FROM SOLID DISPERSIONS 
RESULT AND DISCUSSION: The drug content of all dispersions was found to be in between $99 \%$ to $101 \%$ and the $\%$ yield within $100 \%$ to $101 \%$. The codes of the prepared dispersions and the solubility profile of Mesalamine and its different dispersions with polymers are shown in table 1 . The solubility of Mesalamine in water was found to be approximately $1.09 \mathrm{mg} / \mathrm{ml}$. significantly increase in solubility was obtained for all dispersions of Mesalamine with hydrophilic polymers. Maximum solubility was observed in $\mathrm{S}_{3}$, considered as optimized solid dispersion of drug. Increase in solubility may be due to hydrophilic nature of the polymers, decreased agglomeration and aggregation of drug particles, particle size reduction to molecular size.

Another probable theory concerns to an increasing effective Solubilization process by carriers in the microenvironment (diffusion layer) immediately surrounding the drug particles. Solubility increases with increase in carrier concentration. In summary, the order of solubility was found to be $S_{3}>U_{3}>S_{2}>S_{1}>U_{2}$ $>U_{1}>$ PD (As shown in Table no 2). As expected, the dissolution rate of pure Mesalamine was extremely poor with only about $47.76 \%$ of drug released within $30 \mathrm{~min}$ of the dissolution run (fig. 10). As stated this observations might be attributed to poor wettability and particle agglomeration during the run. When incorporated into solid dispersions, the dissolution rate of Mesalamine from all dispersions was significantly higher than that of pure Mesalamine (Fig. 10) the most rapid dissolution was observed with the $\mathrm{S}_{3}$ solid dispersion in comparison with the other dispersions.

The fastest dissolution from $\mathrm{S}_{3}$ dispersion might be attributed to the solubilizing effects of $S_{3}$ on the active drug. Overall, the increase in dissolution rates of drugs with different carriers and their combinations may be due to lower contact angle, improved wettability and increased surface area. FTIR study (Fig. 2, 3, 4, 5 \& 6) of Mesalamine and its different dispersions showed decrease in intensity of peaks of functional groups as compared to the drug Mesalamine, indicating the decrease in crystalinity. XRPD study (Fig. 7, 8 \& 9) reveals the physical interaction between the drug and polymers.
All prepared dispersions showed changes in the number of peaks or few diffuse peaks were observed in all dispersions as compared to XRPD spectra of raw Mesalamine drug, which indicate decrease in crystalinity in dispersed Mesalamine. The decreased drug crystallite size can explain the faster dissolution and increased solubility, which indicates that there is physical interaction between drug and polymers (fig. 10).

ACKNOWLEDGEMENT: The authors wish thank to Sun Pharmaceutical Ltd. Gujarat (India) for providing Mesalamine as gift sample for this research work.

\section{REFERENCES:}

1. Christian L, Jennifer D., Improving drug solubility for oral delivery using solid dispersions., European Journal of Pharmaceutics and Biopharmaceutics., 50 (2000), 47-60.

2. Sekiguchi K, Obi N., Studies on absorption of eutectic mixtures. I. A comparison of the behavior of eutectic mixtures of sulphathiazole and that of ordinary sulphathiazole in man, Chem. Pharm. Bull., 9 (1961), 866-872.

3. Goldberg A.H, Gibaldi M, Kanig J.L, Mayersohn M., Increasing dissolution rates and gastrointestinal absorption of drugs via solid solutions and eutectic mixtures IV - chloramphenicol-urea system, J. Pharm. Sci. 55, (1966), 581-583.

4. Mura P, Faucci M.T, Manderioli A, Bramanti G, Parrini P, Thermal behavior and dissolution properties of naproxen from binary and ternary solid dispersions, Drug Dev. Ind. Pharm. 25 (1999) , 257-264.

5. Punitha.S, Karthikeyan. D, Devi.P and Vedha Hari.B.N, Enhancement of Solubility and Dissolution of Celecoxib by Solid dispersion technique, Journal of Pharmaceutical Sciences and technology Vol.1(2),2009,63-68.

6. Serajuddin A.T. Sold dispersions of poorly water soluble drugs: Early promises, subsequent problems and recents breakthroughs. J.Pharm.Sci., (1999); 881058-1066.

7. Otagiri M, Imai T, Matsuo N, Uekama K. Improvements to some pharmaceutical properties of Flurbiprofen by $b$ - and gCyclodextrins complexations. Acta Pharma.Suec. 1983; 20:1-10.

8. Miralles MJ, McGinity JW, Martin A. Combined water soluble carriers for co precipitates of Tolbutamide. J.Pharm.Sci; 1982; 71: 30-40.

9. Jejurkar L. S, Tapar K.K., Game M.D, Birari T. K and Ghenge G. R, Development and Validation of Spectrophotometric Method for Mesalamine in Pure and In Tablets, Research J. Pharm. and Tech. 4(4): April 2011, 589-591.

10. Alonso MJ, Maincent P, Garci-Arias T, Vila-Jato JL.A comparative biopharmaceutical study of fresh and ageing TolbutamidePolyethylene Glycol solid dispersion. Int.J.Pharm. 1988; 42:2733

11. Betageri GV, Makarla KR. Enhancements of dissolution of Gluburide by solid dispersion and Lyophilization techniques. Int.J.Pharm., 1995; 126:155-160 